\title{
O experimentalismo poético em Portugal
}

\author{
Fernando Aguiar* I Poeta, Professor e Ensaísta
}

Resumo: Reflexão acerca da poesia concreta em Portugal: experimentalismo poético, publicações, revistas e principais protagonistas.

Palavras-chave: poesia concreta em Portugal, revistas e exposição de arte.

Se considerarmos que o poema "Solidão" de José-Alberto Marques, publicado no jornal do Colégio Andrade Corvo, em 1958, foi a primeira obra de poesia concreta publicada em Portugal, podemos concluir que a poesia visual portuguesa irá também, muito em breve, comemorar o seu $50^{\circ}$ aniversário.

E embora já existisse alguma actividade prenunciadora de uma escrita de vanguarda como, por exemplo, os livros POEMAS PROPOSTOS de Jaime Salazar Sampaio (1954) e ABANDONO VIGIADO de Alexandre O'Neill (1960), assim como o artigo de Ana Hatherly sobre poesia concreta publicado no jornal Diário de Notícias em 1959, com a proposta de um poema concreto, o aparecimento da poesia experimental em Portugal foi de certo modo precedido com a edição de uma pequena antologia de Poesia Concreta do

* Fernando Aguiar. Professor, poeta e ensaísta. Tem inúmeros livros publicados em Portugal. 
Grupo Noigandres, publicada em 1962 pela Embaixada do Brasil em Lisboa, no mesmo ano em que E. M. de Melo e Castro publica IDEOGRAMAS, o primeiro livro português de poesia experimental.

O facto de em Portugal não ter existido um grupo estruturado de poetas concretos terá sido a principal razão da não existência de um manifesto, procedimento usual em movimentos deste tipo. No entanto, essa circunstância não impediu que poetas como Ana Hatherly, António Aragão, E. M. de Melo e Castro ou Salette Tavares se reunissem para produzir revistas, exposições e happenings. O seu trabalho criativo contribuiu inclusivamente para a divulgação da poesia concreta noutros países europeus, como foi o caso da carta que E. M. de Melo e Castro enviou ao suplemento literário do Times em 1962 que, segundo o testemunho de Don Sylvester Houéddard no catálogo da exposição "QUADLOG" (1968), e de John Sharkey na antologia MINDPLAY (1971) influenciou poetas ingleses e escoceses a desenvolverem trabalhos de poesia concreta.

No princípio da década de 60 a poesia experimental era bastante contestada e criticada por um intelectualismo em decadência e pouco aberto a experiências e a inovações. Foi neste contexto que em Julho de 1964 apareceu o primeiro número da revista Poesia Experimental, organizada por António Aragão e Herberto Helder, e que contava com a colaboração de António Barahona da Fonseca, António Ramos Rosa, E. M. de Melo e Castro e Salette Tavares.

No ano seguinte estes mesmos autores (excepto António Ramos Rosa) apresentaram a exposição "VISOPOEMAS", no âmbito da qual teve lugar o Concerto e Audição Pictórica, o primeiro happening realizado em Portugal. Esta acção de carácter "neodadaísta" foi executada por António Aragão, Clotilde Rosa, E. M. de Melo e Castro, Manuel Baptista e Salette Tavares, com a colaboração dos músicos Jorge Peixinho e Mário Falcão.

Outro acontecimento marcante foi a publicação de um suplemento especial do Jornal do Fundão em Janeiro de 1965, dedicado à poesia concreta, com artigos teóricos e poemas experimentais, organizado por António Aragão e por E. M. de Melo e Castro. Ainda em 1965, E. M. de Melo e Castro publica o livro "PROPOSIÇÃO 2.01 - POESIA EXPERIMENTAL", um importante ensaio teórico seguido de uma antologia de poemas internacionais.

No ano seguinte é editada a revista Poesia Experimental 2, e em 1967 foram lançadas em simultâneo as revistas Operação 1 e Operação 2, na Galeria-Livraria Quadrante. Operação 1 era constituída por "textos criadores e 
críticos sobre a estrutura do fenómeno poético", de Ana Hatherly, José-Alberto Marques, António Aragão, Pedro Xisto e E. M. de Melo e Castro, enquanto que Operação 2 era totalmente preenchida com "Estruturas Poéticas", de Ana Hatherly, "uma investigação estrutural de determinadas formas linguísticas aplicadas à criação poética”.

No lançamento destas revistas realizou-se "Conferência-Objecto", que foi o segundo happening a ter lugar em Portugal. Ana Hatherly, José-Alberto Marques, E. M. de Melo e Castro, Jorge Peixinho e um gravador, foram os participantes nesse evento, assumindo-se como "provocadores do acto criador, exemplificando a diferença e a simultaneidade que há entre o "estruturado" e o "improvisado".

Este happening, assim como a publicação da revista Hidra 2 (com Nei Leandro de Castro, Liberto Cruz, José-Alberto Marques, António Aragão, Silvestre Pestana e E. M. de Melo e Castro) e a edição em 1971 do primeiro romance experimental português, UM BURACO NA BOCA de António Aragão, encerraram de certo modo o período mais polémico deste movimento, e contribuíram para afirmar a poesia experimental na literatura portuguesa.

Simultaneamente, e com a edição da ANTOLOGIA DA POESIA CONCRETA EM PORTUGAL em 1973, conclui-se também a fase mais "concretista" do movimento que passou a ser, principalmente depois da Revolução de Abril de 1974 mais "experimentalista", no sentido de enveredar por novas soluções poéticas e plásticas que já não se limitavam à simples construção minimalista da palavra e da sua colocação espacial na página.

A ANTOLOGIA DA POESIA CONCRETA EM PORTUGAL organizada por José-Alberto Marques e por E. M. de Melo e Castro, reuniu poemas de 14 autores: Abílio-José Santos, Alberto Pimenta, Alexandre O’Neill, Ana Hatherly, António Aragão, E. M. de Melo e Castro, Herberto Helder, Jaime Salazar Sampaio, José-Alberto Marques, José Luis Luna, Liberto Cruz, Luis Pignatelli, Salette Tavares e Silvestre Pestana. Três anos depois, Josep M. Figueres e Manuel de Seabra organizam a ANTOLOGIA DA POESIA VISUAL EUROPEIA constituída por obras de variadíssimos poetas, incluindo os portugueses Ana Hatherly, António Aragão, E. M. de Melo e Castro, Liberto Cruz, Manuel de Seabra e Silvestre Pestana, que veio dar uma visão mais alargada da poesia experimental que se produzia na Europa (até aí pouco conhecida em Portugal), muito pela forte componente visual e plástica de muitos dos poemas antologiados, alguns deles sem qualquer signo verbal, o que veio colocar a polémica questão de se 
saber se uma obra criativa pode ser considerada como um poema visual apesar de não ter qualquer palavra ou letra.

Estas duas antologias foram fundamentais para a divulgação da poesia experimental, que ainda assim acabou por manter sempre uma certa marginalidade em relação aos meios literários e das artes plásticas, ao contrário do que aconteceu com o concretismo no Brasil.

Em 1977 três acontecimentos ajudaram a afirmar a noção de poesia-acção, de intervenção poética e, de uma maneira geral, da poesia como acto e como vivência. Na Galeria Quadrum, Ana Hatherly realizou uma intervenção intitulada "Rotura", que consistia em rasgar violentamente diversos painéis em papel de cenário, numa atitude de revolta contra a arte como objecto de consumo e de "puro investimento monetário". A segunda acção efectuouse numa tarde de domingo, no Jardim Zoológico de Lisboa, onde Alberto Pimenta escandalizou toda a gente ao expor-se numa jaula (com o letreiro "Homo Sapiens") ao lado de outras jaulas com símios, e a terceira foi constituída por um espectáculo do grupo "Ânima", com a encenação de poemas experimentais de diversos autores.

Ainda em 1977 é de salientar a participação de 12 poetas experimentais portugueses na XIV Bienal de S. Paulo, incluída na secção Grandes Confrontos - Poesia Espacial.

Em 1980 inaugurou em Lisboa, na Galeria Nacional de Arte Moderna PO.EX, uma importante exposição de poesia de vanguarda organizada por E. M. de Melo e Castro, e onde participaram com poemas visuais, instalações, acções poéticas, filmes experimentais e video, António Aragão, António Campos Rosado, Ana Hatherly, António Barros, E. M. de Melo e Castro, José-Alberto Marques, Salette Tavares e Silvestre Pestana.

Na sequência desta exposição, Ana Hatherly e E. M. de Melo e Castro publicaram no ano seguinte o livro PO.EX - Textos Teóricos e Documentos da Poesia Experimental Portuguesa, um estudo bastante completo sobre todo o movimento experimental desde o princípio dos anos 60 , e inclui os mais importantes textos teóricos escritos até à altura, cronologia dos principais acontecimentos, artigos diversos, cartas, críticas, etc.

Com a exposição e o livro PO.EX termina de certo modo (visto que estas datas não são estanques e que este tipo de transições se vão diluindo no tempo) o período da "poesia experimental", para se entrar gradualmente numa fase em que a componente "visual" do poema se torna cada vez mais presente e com um maior "peso" na criação do poema. 
Em 1983 Silvestre Pestana realizou os primeiros computer-poems para "spectrum", e Ana Hatherly publica o livro A EXPERIÊNCIA DO PRODÍGIO - Bases Teóricas e Antologia de Textos-Visuais Portugueses dos Séculos XVII e XVIII, que é um estudo notável sobre Textos-Visuais da Poesia Barroca Portuguesa, textos que se podem considerar como que a arqueologia da poesia experimental.

Pode-se considerar que o ano de 1985, com a edição do livro POEMOGRAFIAS - Perspectivas da Poesia Visual Portuguesa inicia a fase da "poesia visual" (termo que passa a ser comummente utilizado a partir dessa data nas actividades relacionadas com a "poesia experimental"). A antologia, organizada por Fernando Aguiar e por Silvestre Pestana, pretendia ser um ponto da situação da poesia que se estava a produzir na altura e ao mesmo tempo perspectivar teoricamente os caminhos que a poética com um carácter experimental iria percorrer num futuro próximo, na opinião de cada participante. O livro foi assim constituído por depoimentos teóricos e por vários poemas visuais mais ou menos ilustrativos dessa teoria, material praticamente todo inédito de AbílioJosé Santos, Alberto Pimenta, Ana Hatherly, Antero de Alda, António Aragão, António Barros, E. M. de Melo e Castro, Fernando Aguiar, José-Alberto Marques, Salette Tavares e Silvestre Pestana. Incluiu ainda os depoimentos do crítico de arte Egídio Álvaro sobre poesia visual e do músico Jorge Lima Barreto, que revelava a preocupação dos organizadores em diluir as barreiras entre as diversas formas de arte.

Na sequência da publicação desta antologia e da exposição itinerante POEMOGRAFIAS que complementava a edição do livro, assiste-se a um aumento das actividades colectivas com a realização de exposições, um Festival de Poesia Viva, apresentação regular de performances poéticas e secções de revistas estrangeiras dedicadas à poesia visual portuguesa. No campo individual editam-se vários livros, novos poetas integram as actividades colectivas a partir da segunda metade dos anos 80 e, pela primeira vez, a poesia visual vai actuar de uma maneira mais evidente no campo das artes plásticas.

Para isso contribuiu a exploração de novas formas expressivas e a actuação de poetas mais jovens que trouxeram uma visão mais abrangente da criação poética: as performances e as instalações de António Barros, Fernando Aguiar e Silvestre Pestana, os primeiros computer-poems de Silvestre Pestana, as experiências de infopoesia de E. M. de Melo e Castro, a foto-poesia explorada por Fernando Aguiar ou os trabalhos de electrografia realizados por António Aragão, António Dantas, António Nelos e César Figueiredo. 
O eixo e a roda: $v .13,2006$

Disponivel em: http://www.letras.ufmg.br/poslit

Das actividades colectivas que se intensificaram desde essa data até ao princípio dos anos 90 destacam-se a exposição inaugural da I Bienal Internacional de Poesia Visual y Experimental en México, dedicada à representação portuguesa (1985), o № 80/87 da revista francesa "Doc(k)s" sobre Portugal, com uma extensa selecção de poemas visuais e fotografias de performances (1987), o $1^{\circ}$ Festival Internacional de Poesia Viva, que contou com uma ampla exposição de poesia visual (219 participações de 29 países) nas suas múltiplas variantes incluindo uma mostra, pela primeira vez em Portugal, de obras de Holo-Poesia, de autoria de Eduardo Kac, e de um Simpósio que teve a presença de vários poetas portugueses e estrangeiros. O Festival foi organizado por Fernando Aguiar, assim como a exposição realizada no ano seguinte (1988) no Museu de Setúbal, intitulada "POESIA:OUTRAS ESCRITAS, NOVOS SUPORTES".

Em 1989 Fernando Aguiar e Gabriel Rui Silva organizaram a exposição "CONCRETA. EXPERIMENTAL. VISUAL - Poesia portuguesa 19591989", que comemorava os 30 anos de poesia experimental em Portugal, considerando que na altura o "1ํPoema Concreto" de Ana Hatherly, publicado em 1959, era a mais antiga obra poética conhecida nesta área. A exposição foi apresentada na Universidade de Bolonha, em Itália (1989), em 1990 no Centro Cultural Português em Paris, em 1991 na Universidade de Lyon e, no ano seguinte, na Universidade de Poitiers, também em França. Curiosamente nunca foi possível apresentá-la em Portugal. Participaram praticamente todos os poetas que colaboraram mais assiduamente nas manifestações de poesia experimental nos anos 70 e 80, e outros mais jovens que começaram a integrar os eventos colectivos, como António Nelos, Gilberto Gouveia, António Dantas, Emerenciano, Gabriel Rui Silva, César Figueiredo, Armando Macatrão e Avelino Rocha.

Depois de 30 anos de prática poética, surgem as primeiras grandes antologias de alguns dos poetas históricos do movimento. E. M. de Melo e Castro edita TRANS(A)PARÊNCIAS (1990), que inclui todos os seus poemas concretos e experimentais, ficando de fora os poemas mais "visuais"; Alberto Pimenta reúne a maior parte dos seus trabalhos na OBRA QUASE COMPLETA (1990); Salette Tavares edita OBRA POÉTICA (1992), constituída por todos os seus livros anteriores, incluindo numerosos inéditos, e a Fundação Calouste Gulbenkian promove a exposição antológica OBRA VISUAL (1992), com trabalhos de 1960 a 1990, com a edição de um completo catálogo..

A revista brasileira Dimensão № 22, dirigida pelo poeta Guido Bilharinho, dedica também em 1992, uma secção especial à poesia experimental 
portuguesa, com poemas de A. Aragão, C. Figueiredo, A . Hatherly, A . Pimenta, F. Aguiar, A.J. Santos, A. e Sousa e S. Tavares. No ano seguinte, Manuel Portela organiza no Museu Municipal Dr. Santos Rocha, na Figueira da Foz "WOR(L)D POEM / POEMA MU(N)DO”, uma exposição internacional de poesia visual, com a edição de um importante catálogo.

A partir da segunda metade dos anos 90 verifica-se um abrandamento nas actividades colectivas e uma maior incidência nas produções individuais. Quer a nível de exposições, publicação de livros ou apresentação de intervenções poéticas, tendência que se tem mantido até agora.

Com o falecimento de Abílio-José Santos em 1993, de Salette Tavares em 1994 e com a doença de António Aragão, que deixou de produzir desde o final dos anos 80, os restantes poetas "históricos" têm desenvolvido o seu trabalho na publicação de romances ou de uma poesia mais próxima do verbal (José-Alberto Marques e Alberto Pimenta), E. M. de Melo e Castro viveu alguns anos em S. Paulo onde, paralelamente à sua actividade docente editou alguns livros no Brasil, e Ana Hatherly, que embora também tenha publicado regularmente, tem tido uma maior visibilidade através das exposições individuais e na participação de exposições colectivas.

De uma segunda geração, António Barros deixou de trabalhar neste campo desde meados dos anos 80, Silvestre Pestana tem-se dedicado sobretudo à escultura e Fernando Aguiar reduziu bastante a sua actividade como organizador e dinamizador da poesia visual para se dedicar mais activamente à criação poética e plástica, realizando regularmente exposições de poesia visual, instalações, fotografia e pintura, sempre relacionadas com a palavra, e tem participado em numerosos Festivais de Poesia e de Performance em vários países.

Dos poetas que integraram o movimento a partir dos anos 80, praticamente todos reduziram bastante o seu trabalho poético-experimental para se dedicarem a outras actividades. De referir, no entanto, a produção de César Figueiredo com a electropoesia, e de Almeida e Sousa e Manuel Portela com um importante trabalho ligado à poesia feita por computador e à poesia hiper-média. Neste campo, Rui Torres, professor da Universidade do Porto, está também a desenvolver um trabalho bastante interessante e, simultaneamente, a coordenar um inédito e importante projecto de investigação e catalogação da poesia concreta em Portugal, com o objectivo de a divulgar pelas Universidades e escolas do país, estudo que mais tarde se irá estender aos anos 80. E também o trabalho pioneiro de Américo Rodrigues na poesia 
sonora, tendência que nunca teve grande expressão em Portugal, tendo já gravado 2 CD's com obras suas neste domínio.

Em 1999 o Museu de Arte Contemporânea de Serralves dedicou a sua segunda exposição (depois da colectiva de inauguração do Museu) à poesia experimental portuguesa, com a maior exposição antológica realizada até hoje, intitulada "O EXPERIMENTALISMO PORTUGUÊS ENTRE 1964 E 1984", que reuniu obras de Abílio-José Santos, Alberto Pimenta, Ana Hatherly, António Aragão, António Barros, E. M. de Melo e Castro, Fernando Aguiar, José-Alberto Marques, Liberto Cruz, Salette Tavares e Silvestre Pestana. Infelizmente o catálogo preparado para a ocasião, que seria igualmente o mais completo documento sobre a história da poesia experimental, por razões diversas nunca chegou a ser editado.

No final de 2004, os professores Carlos Mendes de Sousa e Eunice Ribeiro publicaram a ANTOLOGIA DA POESIA EXPERIMENTAL PORTUGUESA. ANOS 60 - ANOS 80, que apresenta, para além de um estudo introdutório, uma extensa recolha das principais obras, organizadas por décadas, o que permite uma visão histórica e evolutiva da poética portuguesa com um carácter de vanguarda. Outro aspecto a assinalar, é que esta é a primeira antologia organizada por autores exteriores ao movimento, o que resulta numa diferente leitura do movimento e dos seus protagonistas.

Já este ano, o Museu de Serralves, dedicou uma significativa exposição retrospectiva da obra de E. M. de Melo e Castro, com obras de quase 50 anos de actividade como poeta concreto e experimental, e com um completo catálogo que documenta o percurso criativo desta figura histórica do experimentalismo português. E estão previstas para os próximos anos exposições antológicas de Ana Hatherly, Fernando Aguiar e de Salette Tavares.

Nos anos mais recentes tem-se verificado um novo interesse pela poesia experimental e visual por parte dos meios universitários, com diversos estudos e algumas teses sobre o movimento, e a criação de disciplinas que abordam a poesia de vanguarda em Portugal.

Abstract: Reflections over the concrete poetry in Portugal: poetic experimentalism, publications, magazines and main protagonists. Key words: concrete poetry in Portugal, magazines and art expositions. 